\title{
Study on the knowledge, attitudes and practices regarding prevention of recurrent falls in the elderly.
}

\author{
Smitesh Gutta ${ }^{1}$, Aneez Joseph ${ }^{2}$, Arup Chakraborty ${ }^{3}$, Anu Mary Alexander ${ }^{4}$ \\ 1,2,3,4 (Department Of Community Medicine, Christian Medical College, Vellore, Tamil Nadu, India)
}

\begin{abstract}
Prevention of recurrent falls in the elderly is now increasingly important in developing countries. A cross sectional study was undertaken in Vellore, South India, to describe the knowledge, attitudes and practices regarding prevention of recurrent falls among elderly with a previous history of a fall, as well as their caregivers. $45 \%$ of the elderly had a repeat fall after the age of 60 years owing mainly to poor vision, osteoporosis, anemia or the use of more than 3 chronic medications. Both the elderly and the caregivers were found to have poor knowledge regarding prevention of falls. Health education (OR 0.418; 95\% CI: .176-.991) and compliance to a prescribed intervention for at least 6 months (OR 0.088; 95\% CI: .032-.244) were found to be associated with less of repeat falls. Health education with emphasis on the benefits of compliance to prescribed interventions may help prevent recurrent falls.
\end{abstract}

Keywords: elderly, health education, intervention, prevention, recurrent fall.

\section{Introduction}

Worldwide, the number of persons over 60 years is growing faster than any other age group ${ }^{1}$. In India older persons at or over the age of 60 constitute above $7.7 \%$ of the total population, using more than 30 percent of the medical expenditure of the nation ${ }^{2,3}$. Unintentional injuries was the leading cause of morbidity and mortality among the elderly ( $>60 \mathrm{yrs})$ in the United States, of which falls were the leading cause ${ }^{4}$. Prospective studies have reported that $30 \%$ to $60 \%$ of community - dwelling elderly fall each year, with approximately half of them experiencing recurrent falls ${ }^{5}$. In India, the proportion of deaths from unintentional injuries was $30 \%$ among those $>60$ years, with $65 \%$ attributable to falls ${ }^{6}$. Joshi et al (2003) conducted a cross-sectional survey of urban and rural elderly and found that $51.5 \%$ had reported falls ${ }^{7}$. Although falls are an important preventable problem, the effect of interventional strategies in the community has not been studied. Most falls experienced by older people result from multiple etiological factors. Preventing falls in individuals requires the identification and use of multiple interventions. Studies have shown association between the use of commonly used interventions and risk of fall in the elderly. Lamoreux et al (2008) have shown an association between severe visual impairment and falls in older persons, implying that prevention, detection, and treatment of vision-related factors can reduce the risk of falls in older people ${ }^{8}$. Supplements of vitamin D and calcium can help in improving musculoskeletal function accounting for upto $49 \%$ reduction of falls ${ }^{9}$, while physical exercise reduces the risk of falls in elderly by improving motor functions ${ }^{10}$. Tinetti et al (2003) showed that the use of four or more prescription medications was a risk factor for falls in older people and modification of these drugs can help in reducing the risk of falls ${ }^{11}$. Anemia in the elderly has been associated with twice the risk of recurrent falls suggesting that treatment with iron supplements may reduce falls ${ }^{12}$. A review article on falls in the elderly by Krishnaswamy et. al found that there was no study done to assess the usefulness of interventional strategies for the Indian elderly ${ }^{2}$. Karen Hughes et al (2008) showed that residents from a previous-intervention community, which experienced fall-prevention program, were more likely to believe that falls were preventable and to prioritize the prevention of falls ${ }^{13}$. In this study it was found that $65.6 \%(\mathrm{n}=1989)$ of people disagreed with the statement that "falls are not preventable". Hence, if communities are educated about falls and shown that the use of commonly used interventions is effective in reducing the risk of recurrent fall, they may be more likely to accept these interventions and prioritize prevention of recurrent falls in the elderly. The present study was carried out to describe the knowledge and attitudes among elderly about prevention of recurrent fall and to compare the rates of utilization of interventions for prevention of recurrent falls among urban and rural elderly. The study also assessed the perception and attitudes of caregivers about falls in the elderly and prevention of recurrent falls.

\section{Methodology}

A cross-sectional study using a structured questionnaire was carried out in a rural development block with a population 1, 06,000 and in an urban area of Vellore, Tamil Nadu, and South India. A structured questionnaire was used to interview the elderly to study the use of interventions for prevention of recurrent falls. Focus group discussions were held among caregivers to study their perceptions towards falls in the elderly. 


\subsection{Sample size}

A sample size of 90 was required to assess the knowledge and attitude among elderly about prevention of recurrent falls, assuming that $65.6 \%$ of the elderly in both urban and rural areas have poor knowledge and attitude ${ }^{13}$. A sample size of 96 (48 in each group) was needed to compare the rates of utilisation of interventions for prevention of recurrent falls, assuming 30\% among rural and $60 \%$ among the urban elderly ${ }^{7}$.

\subsection{Criteria for selection}

Elderly (age equal to or more than 60 years) with a previous history of at least one fall were eligible for participation in the quantitative study. For the study, a fall was defined as "inadvertently coming to rest on the ground, floor or other lower level, excluding intentional change in position to rest in furniture, wall or other objects" ${ }^{1}$ Those who were bed-ridden and those who had a fall due to road traffic accidents were excluded. Caregivers of the elderly, in the age group of 30-45 years, were invited for the focus group discussions.

\subsection{Sampling}

In the rural area 8 villages were selected by simple random sampling and 6-7 eligible participants in each village were surveyed. Survey was carried out in both rural and urban areas by starting at a random point and then going door to door until the required numbers of elderly persons who met the inclusion criteria and gave informed consent were obtained.

\subsection{Data collection}

The questionnaire contained demographic details, fall related information, questions assessing the knowledge and attitude regarding intervention for prevention of recurrent fall, details of the interventions taken and subsequent falls after initiation of intervention(s). The interventions included were vision correction (spectacle, cataract surgery), better lighting, vitamin D / calcium supplements, and exercises, treatment for incontinence, iron supplements, alcohol deaddiction and modification of chronic medications.

Focus group discussions were carried out (one each in urban and rural areas) to assess caregivers' perceptions on falls in the elderly and the role of preventive measures. The various themes which were discussed were importance of falls, common causes of falls, prevention of falls, effectiveness and implementation of interventions. The moderators were social workers while two of the investigators were scribes.

\subsection{Data Analysis}

The data was entered in Epi-info and analyzed using the statistical package for the social sciences (SPSS for Windows, version 16.0 Chicago: SPSS Inc). Analysis of data was done by describing the knowledge and attitudes among elderly about prevention of recurrent falls, comparing the rates of utilization of interventions for prevention of recurrent fall among urban and rural elderly and analyzing the association between regular use of any of the existing interventions and subsequent falls. Analysis of the focus group discussion was done by assessing the perception and attitudes of caregivers about falls in the elderly and prevention of recurrent falls.

\subsection{Ethical Clearance}

The study was approved by the Institutional Review Board and ethics committee of the Christian Medical College, Vellore, India.

\section{Results}

The various socio-demographic characteristics of the study population are shown in Table 1. In both urban and rural areas, nearly two-thirds of the participants were women. The mean age of the participants was 71 years and $62 \%$ of the study population was illiterate. Majority was not currently employed gainfully and the women were mainly involved in household work. 38 percent of the study population either lived alone or in nuclear families.

\subsection{Fall related Informations}

45 percent of the elderly were found to have fallen more than once, with one-third having fallen 4 or more times. 77 percent of the falls in the study population occurred in the age group of 60-70 years (Table 2).

60 percent of those who had a second fall had fallen within a span of 1 year. 33\% did not recover completely after the first fall and $32.8 \%$ of those who recovered completely tried to restrict their usual activities due to fear of recurrent falls. The main reported causes of falls were poor vision $(20 \%)$, osteoporosis $(17 \%)$ anemia (13\%) and use of more than 3 chronic medications (7\%). The other causes included loss of balance $(9 \%)$, alcohol (5\%), cerebrovascular accidents (5\%), poor lighting (5\%), hypertension (4\%), peripheral 
neuropathy $(3 \%)$, hypoglycemia $(2 \%)$, seizure disorder $(2 \%)$, heart disease $(2 \%)$, myalgia $(1 \%)$, urinary incontinence (1\%), slippery floor $(1 \%)$ and unknown causes $(5 \%)$.

\subsection{Knowledge and attitude assessment}

Only 12 percent of the elderly disagreed with the statement "Older people fall and there is nothing that can be done to prevent falls" (Table 3). However $68 \%$ of the participants believed that once a person falls, steps can be taken to prevent recurrent falls. $52 \%$ of the participants believed that the intervention which was given to them could prevent recurrent falls. This optimistic attitude of the elderly towards the interventions was found to be associated with less chances of a repeat fall. $(\chi 2=14.303$, $p$ value $=0.000)$.

\subsection{Use of interventions}

Overall $79 \%$ of study population sought medical help after the first fall. Elderly in rural areas $(86 \%)$ sought medical help more than urban areas (72\%). Only $6.98 \%$ of study population who sought medical help in the rural areas had visited traditional healers after a fall (Table.4). Majority of the elderly in both rural (74.4\%) and urban $(83.3 \%)$ areas were informed about the cause of the fall by the health care provider. However, only two-thirds of the elderly took any intervention after the first fall in both urban and rural areas. A doctor was more often the main initiator of the intervention in urban (96.8\%) as compared to rural areas (81.8\%). Only onethird of the elderly in both urban (38\%) and rural areas (32\%) received health education about falls. Elderly in the rural areas were less educated about the need for intervention to prevent recurrent fall when compared with the elderly from the urban areas $(63.6 \%$ and $77.4 \%$ respectively).The compliance to intervention was also found to be more in the urban areas (70.97\%) when compared to the rural areas (57.6\%).Table 5 shows the distribution of types of prescribed interventions. In rural areas, the most common interventions were calcium/vitamin D supplementation $(24.2 \%)$ and correction of vision, while in the urban areas it was modification of chronic medications $(29 \%)$ and the use of iron supplementation (19.4\%).There was a strong association between taking any prescribed intervention regularly for at least 6 months and less chance of a repeat fall (OR $0.088 ; 95 \%$ CI: $.032-.244$ ). Receiving health education was also associated with less chance of a repeat fall (OR $0.418 ; 95 \%$ CI: $.176-.991)$.

\subsection{Focus Group Discussion}

The group in the rural and the urban areas comprised of 8 and 12 caregivers respectively, with almost equal gender distribution. The summary of the outcome of the focus group discussion is described in Box 1 . Opinions expressed included the fact that knowledge regarding prevention of falls is lacking and also that the elderly themselves are not always willing to cooperate.

\section{Discussion}

In this study we found that $45 \%$ of the participants had more than 1 fall after the age of 60 years with $15 \%$ having 4 or more falls. This is higher than a study done by Chu L.W. et al (2005) which had found that in ambulatory Chinese elderly, $24.5 \%$ of the fallers had recurrent falls with $1.3 \%$ of the fallers having 4 or more falls ${ }^{14}$. However, prospective studies done in the developed countries have also shown that approximately half of those who fall experienced recurrent falls ${ }^{5}$. Out of the 15 cases of 4 or more episodes of fall, 14 cases were in the age group 60-70 years. This may be due to the fact that they are more ambulatory than the older age groups.

One-third of those who recovered completely after the first fall tried to restrict their activities due to fear of recurrent fall. This was similar to an earlier study by Nevitt et. al which found that approximately $25 \%$ of those who had fallen restrict their usual activities (including potentially beneficial behaviors such as physical activity) because of injury or fear of falling again ${ }^{15}$. The leading causes of falls were poor vision, osteoporosis, anemia and use of more than 3 chronic medications which co-relates with studies which have already shown their association with risk of recurrent falls ${ }^{8,9,11,12}$. The knowledge and attitudes of Indian elderly regarding prevention of fall seem poor, as compared to their counterparts in developed nations. An optimistic attitude in believing that the intervention advised after a fall could prevent a further fall was shown to be a strong preventive factor against recurrent falls. This highlights the importance of the need for a health care professional to explain and make an elderly person understand the importance of the intervention, for better compliance and results. The proportion of those who sought medical help after the first fall $(79 \%)$ was higher than found in the study done by Joshi et al (2003) ${ }^{7}$. The study also showed that elderly in rural areas sought medical help more than their urban counterparts. However less awareness about need for interventions for prevention of recurrent falls among rural elderly (63.6\%) compared to urban $(77.4 \%)$ reflected in their poor compliance to the prescribed intervention when compared to urban elderly (57.6\% and $70.97 \%$ respectively). It was interesting to note that only one-third of the elderly in both urban and rural areas received health education about falls showing that this is a possible area of improvement. The study also showed that having received health education was associated with less chance of a repeat fall, emphasizing the importance of health education as an 
important component in fall prevention programs. Compliance to any of the prescribed interventions for a period of at least six months was found to be associated with less chances of a repeat fall. Most of the studies done in developed countries have also suggested use of multi-interventional programmes for prevention of falls in the elderly. The focus group discussion highlighted the fact that while caregivers felt falls were a matter of concern, they also realized that they have poor knowledge about prevention of falls and felt the need for health education.

\section{Limitations}

There was a recall bias as some elderly were unable to remember details of falls. A lack of information at local health centers regarding elderly with history of falls necessitated a labour intensive door to door survey which may not always be feasible.

\section{Conclusions and recommendations}

As there is lack of knowledge regarding the fact that prescribed interventions can reduce recurrent falls, health education is needed in this area for both the elderly as well as the public. People should also be made to understand that falls are preventable and need not be a part of normal ageing. Health professionals should be more careful to identify the causes of falls, inform the family about the cause and then prescribe effective interventions. Follow up of these individuals should be done to monitor compliance. Further research in the form of trials may be required to prove the effectiveness of each specific intervention in prevention of falls in the Indian context.

\section{Acknowledgement}

The authors would like to acknowledge Dr. Anuradha Bose, Professor, Department of Community Health, CMC, and Vellore for her guidance. The authors would like to thank the social workers and health workers who helped in data collection and in the qualitative study. Authors are also thankful to all individuals of rural and urban area of Vellore who participated in the study.

References

[1]. WHO Global Report on Falls Prevention in Older Age. Available from: www.who.int/ageing/publications/Falls_prevention7March.pdf. Accessed April 29, 2011.

[2]. Krishnaswamy B, Usha G.Falls in older people. National/regional review, India. Available from:
www.who.int/ageing/projects/SEARO.pdf. Accessed May 1, 2011.

[3]. Patel JC. Falls in elderly. Indian J Med Sci. 2000; 54(8):350-352.

[4]. Centers for Disease Control and Prevention. Web-based Injury Statistics Query and Reporting System (WISQARS). Available from: www.cdc.gov/injury/wisqars/index.html.Accessed April 28th, 2011.

[5]. Rubenstein LZ, Josephson KR. The epidemiology of falls and syncope. Clin Geriatr Med.2002; 18:141-58.

[6]. Jagnoor J, Suraweera W, Keay L, et al. Childhood and adult mortality from unintentional falls in India. Bull World Health Organ. 2011; 89(10):733-740.

[7]. Joshi K, Kumar R, Avasthi A. Morbidity profile and its relationship with disability and psychological distress among elderly people in Northern India. Int J Epidemiol. 2003; 32(6):978-987.

[8]. Lamoreux EL, Chong E, Wang JJ, et al. Visual Impairment, Causes of Vision Loss, and Falls: The Singapore Malay Eye Study. Invest Ophthalmol Vis Sci. 2008; 49(2):528-533.

[9]. Bischoff-Ferrari HA, Dawson-Hughes B, Staehelin HB, et al. Fall prevention with supplemental and active forms of vitamin D: a meta-analysis of randomised controlled trials. BMJ. 2009;339:b3692.

[10]. Kobayashi R, Nakadaira H, Ishigami K, et al. Effects of physical exercise on fall risk factors in elderly at home in intervention trial. Environ Health Prev Med. 2006; 11(5):250-255.

[11]. Tinetti ME. Preventing Falls in Elderly Persons. N Engl J Med. 2003; 348(1):42-49.

[12]. Penninx BWJH, Pluijm SMF, Lips P, et al. Late-life anemia is associated with increased risk of recurrent falls. $J$ Am Geriatr Soc. 2005;53(12):2106-2111.

[13]. Hughes K, Van Beurden E, Eakin EG, et al. Older persons' perception of risk of falling: implications for fall-prevention campaigns. Am J Public Health.2008; 98(2):351.

[14]. Chu LW, Chi I, Chiu AYY. Incidence and predictors of falls in the Chinese elderly. Ann Acad Med Singapore. 2005; 34(1):60-72.

[15]. Nevitt MC, Cummings SR, Kidd S, Black D. Risk factors for recurrent nonsyncopal falls. A prospective study. JAMA. 1989; 261(18):2663-2668

Table 1: Socio demographic profile of study participants

\begin{tabular}{|c|c|c|c|c|c|c|}
\hline \multirow[b]{3}{*}{ Age group (years) } & \multicolumn{2}{|c|}{ Urban $(n=50)$} & \multicolumn{3}{|c|}{ Rural $(n=50)$} & \multirow{2}{*}{$\begin{array}{l}\text { Total } \\
\mathrm{n}=100\end{array}$} \\
\hline & $\begin{array}{l}\text { Male } \\
(\mathrm{n}=18) \\
\text { number, (percent) }\end{array}$ & $\begin{array}{l}\text { Female } \\
(\mathrm{n}=32) \\
\text { (percent) }\end{array}$ & number, & $\begin{array}{l}\text { Male } \\
(\mathrm{n}=17) \quad \text { number, } \\
\text { (percent) }\end{array}$ & $\begin{array}{l}\text { Female } \\
(\mathrm{n}=33) \quad \text { number, } \\
\text { (percent) }\end{array}$ & \\
\hline & & & & & & \\
\hline Young old (60-74) & $14(77.78)$ & $24(75)$ & & $14(82.35)$ & $24(72.73)$ & 76 \\
\hline Old-old (75-84) & $3(16.67)$ & $8(25)$ & & $3(17.65)$ & $6(18.19)$ & 20 \\
\hline Very old $(>85)$ & $1(5.56)$ & 0 & & 0 & $3(9.09)$ & 4 \\
\hline Education & & & & & & \\
\hline Illiterate & $7(38.89)$ & $21(65.63)$ & & $6(35.29)$ & $28(84.85)$ & 62 \\
\hline
\end{tabular}


Study on the knowledge, attitudes and practices regarding prevention of recurrent falls in the elderly.

\begin{tabular}{|c|c|c|c|c|c|}
\hline $1-5$ years of schooling & $\begin{array}{l}5 \\
(27.78)\end{array}$ & $5(15.63)$ & $4(23.53)$ & $3(9.09)$ & 17 \\
\hline$>5$ years of schooling & $6(33.33)$ & $6(18.75)$ & $7(41.18)$ & $2(6.06)$ & 21 \\
\hline Occupation & & & & & \\
\hline House hold work & 0 & $15(46.88)$ & 0 & $19(27.27)$ & 34 \\
\hline Employed & $4(22.22)$ & 0 & $1(5.88)$ & $1(3.03)$ & 6 \\
\hline $\begin{array}{l}\text { Not } \\
\text { employed } \\
\text { Family }\end{array}$ & $14(77.78)$ & $17(53.13)$ & $16(94.12)$ & $13(39.39)$ & 60 \\
\hline Living alone & $7(38.89)$ & $6(18.75)$ & $1(5.88)$ & $4(12.12)$ & 18 \\
\hline Nuclear family & $4(22.22)$ & $5(15.63)$ & $7(41.18)$ & $4(12.12)$ & 20 \\
\hline Extended family & $1(5.56)$ & $4(12.5)$ & 0 & $2(6.06)$ & 7 \\
\hline Joint family & $6(33.33)$ & $17(53.13)$ & $9(52.94)$ & $23(69.7)$ & 55 \\
\hline
\end{tabular}

Table 2: Fall related information

\begin{tabular}{|ll|}
\hline Questions & Number (\%) \\
How many falls did you have from the age of 60yrs? & $55(55)$ \\
1 & $21(21)$ \\
2 & $9(9)$ \\
3 & $15(15)$ \\
$\geq 4$ & \\
How many years back did you have the 1st fall? & $6(6)$ \\
$<1$ year & $41(41)$ \\
$1-2$ years & $53(53)$ \\
$>2$ years & \\
What was your age at time of fall? & $48(48)$ \\
$60-65$ years & $29(29)$ \\
$66-70$ & $13(13)$ \\
$71-75$ & $10(10)$ \\
$>75$ & \\
Did you recover completely after fall? & $67(67)$ \\
Yes & $33(33)$ \\
No & $(\mathrm{n}=67)$ \\
After recovering completely from the first fall, did you try to restrict your usual activities? & \\
Yes & $22(32.8)$ \\
No & $45(67.2)$ \\
Did you have any subsequent fall? & $45(45)$ \\
Yes & $55(55)$ \\
No & $\mathrm{n}=45$ \\
\hline What was the time duration between the first fall and second fall? & $15(33.3)$ \\
$\geq 6$ months & $12(26.7)$ \\
$7-12$ months & $13(28.9)$ \\
$\geq 24$ months & $5(11.1)$ \\
\hline
\end{tabular}

Table 3: Knowledge and attitudes regarding prevention of falls

\begin{tabular}{|c|c|c|c|c|}
\hline & $\mathbf{N}(\%)$ & $\begin{array}{l}P \text { value for chi } \\
\text { square }\end{array}$ & Odds ratio & $\begin{array}{l}\text { Confidence } \\
\text { interval }\end{array}$ \\
\hline \multicolumn{5}{|c|}{ Older people fall and there is nothing that can be done to prevent falls } \\
\hline Disagree (Ref) & $12(12)$ & \multirow[t]{3}{*}{0.805} & \multirow[t]{3}{*}{0.857} & \multirow[t]{3}{*}{$0.253-2.909$} \\
\hline Agree & $76(76)$ & & & \\
\hline Don’t know & $12(12)$ & & & \\
\hline \multicolumn{5}{|c|}{ Once a person falls he/she can take steps to prevent recurrent falls } \\
\hline Agree (Ref) & $68(68)$ & \multirow{3}{*}{0.546} & \multirow{3}{*}{1.299} & \multirow[t]{3}{*}{$0.555-3.043$} \\
\hline Disagree & $16(16)$ & & & \\
\hline Don’t know & $16(16)$ & & & \\
\hline \multicolumn{5}{|c|}{ Do you think the intervention given to you can prevent recurrent fall? } \\
\hline Yes(Ref) & $52(81.25)$ & \multirow{3}{*}{0.000} & \multirow[t]{3}{*}{0.202} & \multirow[t]{3}{*}{$0.086-0.473$} \\
\hline No & $6(9.38)$ & & & \\
\hline Don’t know & $6(9.38)$ & & & \\
\hline
\end{tabular}


Study on the knowledge, attitudes and practices regarding prevention of recurrent falls in the elderly.

Table 4: Information regarding health care for falls

\begin{tabular}{|c|c|c|c|}
\hline Did you seek medical help after first fall? & $\begin{array}{l}\text { Urban } \\
(\mathrm{n}=50)\end{array}$ & $\begin{array}{l}\text { Rural } \\
(\mathrm{n}=50)\end{array}$ & $\begin{array}{l}\text { Total } \\
(\mathrm{n}=100)\end{array}$ \\
\hline Yes & $36(72)$ & $43(86)$ & $79(79)$ \\
\hline No & $14(28)$ & $7(14)$ & $21(21)$ \\
\hline Where did you seek medical help? & $(n=36)$ & $(n=43)$ & $(n=79)$ \\
\hline Govt. hospital & $11(30.6)$ & $11(25.6)$ & $22(27.8)$ \\
\hline Tertiary care referral institution & $7(19.4)$ & $6(13.95)$ & $13(16.5)$ \\
\hline Private secondary care hospital/clinics & $18(50)$ & $23(53.4)$ & $41(51.9)$ \\
\hline Traditional healers & 0 & $3(6.98)$ & $3(3.8)$ \\
\hline Did the health care provider tell you the cause of the fall? & $(n=36)$ & $(n=43)$ & $(\mathrm{n}=79)$ \\
\hline Yes & $30(83.3)$ & $32(74.4)$ & $62(78.5)$ \\
\hline No & $6(16.7)$ & $11(25.6)$ & $17(21.5)$ \\
\hline After the first fall, did you take any intervention? & $(\mathrm{n}=50)$ & $(n=50)$ & $(\mathrm{n}=100)$ \\
\hline Yes & $31(62)$ & $33(66)$ & $64(64)$ \\
\hline No & $19(38)$ & $17(34)$ & $36(36)$ \\
\hline Initiator of the intervention & $(n=31)$ & $(n=33)$ & $(n=64)$ \\
\hline Doctor & $30(96.8)$ & $27(81.8)$ & $57(89.1)$ \\
\hline Health worker & $1(3.2)$ & $3(9.1)$ & $4(6.25)$ \\
\hline Family & 0 & $3(9.1)$ & $3(4.69)$ \\
\hline Self & 0 & 0 & 0 \\
\hline $\begin{array}{l}\text { Educated about need for intervention to prevent fall in } \\
\text { future }\end{array}$ & $(n=31)$ & $(n=33)$ & $(n=64)$ \\
\hline Yes & $24(77.4)$ & $21(63.6)$ & $45(70.3)$ \\
\hline No & $7(22.6)$ & $12(36.4)$ & $19(29.7)$ \\
\hline Rate your compliance to intervention & $(\mathrm{n}=31)$ & $(n=33)$ & $(n=64))$ \\
\hline Strictly regular & $22(70.97)$ & $19(57.6)$ & $41(64.1)$ \\
\hline Sometimes irregular & $3(9.7)$ & $7(21.2)$ & $10(15.6)$ \\
\hline Only when I feel unwell & $3(9.7)$ & $4(12.1)$ & $7(10.9)$ \\
\hline Not taken at all & $3(9.7)$ & $3(9.1)$ & $6(9.4)$ \\
\hline $\begin{array}{l}\text { After the first fall, did you receive health education about } \\
\text { falls? }\end{array}$ & $(n=50)$ & $(\mathrm{n}=50)$ & $(\mathrm{n}=100)$ \\
\hline Yes & $19(38)$ & $16(32)$ & $35(35)$ \\
\hline No & $31(62)$ & $34(68)$ & $65(65)$ \\
\hline
\end{tabular}

Table 5: Interventions followed for prevention of falls

\begin{tabular}{|lll|}
\hline Intervention & $\begin{array}{l}\text { Rural } \\
\text { Number (\%) }\end{array}$ & $\begin{array}{l}\text { Urban } \\
\text { number (\%) }\end{array}$ \\
Correction of vision & $7(21.2)$ & $5(16.1)$ \\
Calcium/Vit D Supplements & $8(24.2)$ & $7(22.6)$ \\
Iron Supplements & $5(15.2)$ & $6(19.4)$ \\
Modifications of chronic meds & $6(18.2)$ & $9(29)$ \\
Better Lighting & $2(6.1)$ & - \\
Alcohol deaddiction & $1(3.0)$ & - \\
Exercise & - & $2(6.5)$ \\
Treatment of incontinence & - & $1(3.2)$ \\
Others & $4(12.1)$ & $1(3.2)$ \\
\hline
\end{tabular}

Box 1: Results of Focus group discussions

\begin{tabular}{|c|c|}
\hline Theme & Perceptions and examples \\
\hline Importance of fall in elderly & $\begin{array}{l}\text { "We should be concerned about falls in the elderly as the quality of life } \\
\text { is decreased" } \\
\text { "Once an elderly falls, he/she lives a life of pain" } \\
\text { It was also felt that falls were a physical and financial burden for } \\
\text { caregivers. }\end{array}$ \\
\hline $\begin{array}{l}\text { Older people fall and nothing can be done to } \\
\text { prevent it. }\end{array}$ & $\begin{array}{l}\text { "With increase in age, elderly become physically weak, making them } \\
\text { vulnerable to falls" } \\
\text { "We cannot have control over loss of balance in old age and hence } \\
\text { nothing can be done to prevent" }\end{array}$ \\
\hline Common causes of fall in elderly & $\begin{array}{l}\text { Anemia, poor nutrition, chronic diseases like diabetes, hypertension and } \\
\text { poor vision were the commonly perceived causes of fall in elderly. }\end{array}$ \\
\hline How to prevent falls & $\begin{array}{l}\text { Urban areas: "Elderly should restrict their activities and avoid climbing } \\
\text { stairs and travelling." } \\
\text { "We have poor knowledge and need to be educated." } \\
\text { Rural areas: "We have limited resources, whom should we take care of, } \\
\text { old or young?" } \\
\text { "Elderly should go to doctor after a fall and find the cause", }\end{array}$ \\
\hline Most effective intervention & $\begin{array}{l}\text { Urban areas - walking aid e.g. stick. } \\
\text { Rural areas - correction of vision. }\end{array}$ \\
\hline
\end{tabular}


Study on the knowledge, attitudes and practices regarding prevention of recurrent falls in the elderly.

Who should take active role in these Urban areas - "equal responsibility of doctor, health worker, caregiver interventions? and elderly"

"caregivers have extra responsibility as the elderly need to be treated like newborns"

Rural areas - "Doctors and health workers can only advise but it is our responsibility......the elderly should cooperate"

Prevention of recurrent falls

Urban areas - " Can prevent if we know the cause"

Rural areas - "Elderly people will not listen to our advice"

" If we ask to restrict their activities they say they have to work otherwise will become weak"

"If we are educated how we can prevent fall, we can take better care of elderly" 